\title{
LA PLANEACION EDUCATIVA DURANTE EL FRENTE NACIONAL Aportes para su análisis y su historia
}

Han transcurrido ocho años desde que terminó el Frente Nacional; durante esa época de tregua de los partidos tradicionales colombianos, se pusieron en marcha muchas cosas de trascendencia para el país, algunas de las cuales perduran todavía, mientras otras tienden a desaparecer. Entre estas últimas se cuenta precisamente la planeación integral de la educación.

Este libro se generó por la simple constatación de que durante los dieciséis años del Frente Nacional aparecía una serie de documentos de carácter oficial y privado que bajo diversas formas se ocupaban amplia e insistentemente del tema, sin que apareciera un estudio global de los diversos elementos dispersos; el asunto aparecía desde un principio como la espina dorsal de lo que pudiera constituir una historia de la educación durante ese período.

Este trabajo se propone en primer término ser un aporte inicial para facilitar la reflexión y el análisis del tema y en segundo lugar ofrecer materiales para un trabajo histórico más amplio y detallado.

El lector encontrará un recorrido cuidadoso y metodológico a través de las diversas fuentes, hecho dentro de las posibilidades que ofrecían las limitaciones de tiempo y la circunstancia de tratarse de un primer intento de síntesis en este campo. A pesar de esas limitaciones, esperamos que sea de utilidad para los que laboran en el campo educativo ya que cada día se experimenta con más fuerza la necesidad de dejar de lado la improvisación y actuar dentro de planes bien fundados en la realidad y sometidos a continua evaluación.

La división que se hace en doce temas tiende a facilitar la comprensión y el análisis; pero a lo largo de la exposición van jugando tres elementos esenciales que constituyen el meollo de la totalidad; tales elementos son:

1. El concepto del planeamiento integral y el desarrollo del mismo concepto.

2. Las realizaciones o aplicaciones prácticas de la planeación a nivel de organismos o instituciones y de planes de educación generales y particulares.

3. Como consecuencia de la confrontación de los dos elementos anteriores se evidencia constantemente la inadecuación entre la idea y los planes de una parte y las realizaciones concretas, de otra parte; al terminar el Frente Nacional se observa que aún la idea misma se ha perdido; no surgen nuevos planes, al menos de carácter integral.

La presente investigación puede arrojar las siguientes conclusiones:

Durante el Frente Nacional no se desarrolló en la práctica ningún plan educativo integral; pero los repetidos esfuerzos que se hicieron, dejaron mucho de aprovechable y recuperable; por esta razón sería muy conveniente y oportuno que se siguiera ahondando en el tema; pues éste constituye una cantera en la cual se hallan ideas, métodos de trabajo, logros positivos y fracasos que sin duda ayudarían a hacer revivir la planeación 
integral de la educación. Esta actividad, notoriamente ha decaído en los últimos períodos de gobierno; pero no se trata de partir de cero en el momento presente, sino de aprovechar sabia y discrecionalmente las experiencias adquiridas, los recursos humanos existentes y los estudios hechos durante aquellos dieciséis años.

A la acción investigativa y de difusión de ideas, deberá seguir necesariamente una decisión de tipo político, cómo resultado de la convergencia de diversas fuerzas sociales: se lograría así que la planeación educativa se convirtiera en un proceso continuo que superando las meras formulaciones, se hiciera realidad operativa.

De lo anterior se desprende la urgencia de revivir en la actualidad la idea y de reiniciar las actividades tendientes a la planeación integral de todo el sistema educativo, de acuerdo con las verdaderas necesidades del país y con el plan general de desarrollo.

Si el presente trabajo lograra ser un aporte positivo para que la idea del planeamiento integral de la educación cobrara de nuevo la vigencia que tuvo durante el Frente Nacional y para que, en consecuencia, se produjera un cambio de actitud y se reiniciara el proceso planificador de la educación, se habría logrado el objetivo. 